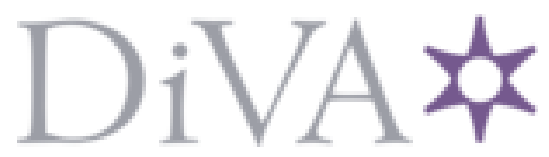

http://www.diva-portal.org

This is the published version of a chapter published in Functional Materials from Renewable Sources.

Citation for the original published chapter:

Li, D., Ibarra, D., Köpcke, V., Ek, M. (2012)

Production of Dissolving Grade Pulps from Wood and Non-Wood Paper-Grade Pulps by

Enzymatic and Chemical Pretreatments.

In: Liebner, F., Rosenau, T. (ed.), Functional Materials from Renewable Sources (pp. 167-189).

American Chemical Society (ACS)

ACS Symposium Series

N.B. When citing this work, cite the original published chapter.

Permanent link to this version:

http://urn.kb.se/resolve?urn=urn:nbn:se:kth:diva-12236 1 
Chapter 9

\title{
Production of Dissolving Grade Pulps from Wood and Non-Wood Paper-Grade Pulps by Enzymatic and Chemical Pretreatments
}

\author{
Dongfang Li, David Ibarra, Viviana Köpcke, and Monica Ek* \\ Department of Fiber and Polymer Technology, \\ KTH Royal Institute of Technology, Teknikringen 56-58, \\ SE 10044 Stockholm, Sweden \\ *E-mail: monicaek@kth.se
}

\begin{abstract}
A raw material with high cellulose content and low content of hemicelluloses, residual lignin, extractives and minerals is required for many important applications in the pharmaceutical, textile, food and paint industries i.e. cotton and dissolving grade pulp are used. However, the high costs for the production of dissolving grade pulps has triggered interest in upgrading paper-grade pulps into dissolving pulps by selective removal of hemicelluloses and subsequent activation of the pulps. This study reports the feasibility to produce dissolving grade pulps from different wood and non-wood paper-grade pulps employing enzymatic and chemical pre-treatments. The results were compared to those of commercial bleached dissolving pulps.
\end{abstract}

\section{Introduction}

The application of regenerated cellulose and cellulose derivatives in pharmaceutical, textile, food, and painting industries results from their specific solubilities, flexibility, and softness. Cellulose, as a raw material, is thought to be nearly inexhaustible in nature, with prominent environmentally friendly and biocompatible properties compared with petroleum-based products (1). Cellulose can be used to produce a number of derivatives, including esters and ethers. Regenerated cellulose is produced in largest amount through viscose 
processes and sometimes through the precipitation of dissolved cellulose from $N$-methylmorpholine- $N$-oxide monohydrate (NMMO) (Lyocell process) (2).

To make products with high quality and homogeneity in a way that can compete with fossil-based products, raw materials with high purity, reactivity and consummate quality control during manufacture are required. Moreover, the recovery of processing chemicals, reagents, and the exploration of suitable purification methods are still difficulties that hamper the production of cellulosic materials in completely replacing fossil fuel-based products.

The starting material for producing the regenerated cellulose and cellulose derivatives is normally dissolving pulp, due to the high purity and reactivity of cellulose. Since the 2000s, the world's demand for dissolving pulp has increased, resulting in a continual and dramatic rise in its price from 300 USD in the 1970s to 1900 USD currently (3). To obtain the highest profits, industries need to find a less expensive alternative as a starting material, acknowledging that this replacement must fulfill certain requirements, such as a high purity of cellulose, a high reactivity, and a suitable degree of polymerization (DP).

Cotton has been used for decades as pure cellulose for the manufacture of cellulose derivatives and products. However, the consumption of cotton has been increasing significantly as a result of heavy needs in textile industries. In addition, the cultivation of cotton requires more water and pesticides than that of trees, which causes problems for the environment (4).

The viscose process was introduced in the 1900s, and it has been developed and applied in modern-day uses despite the fact that the use of carbon disulfide in production flow is a significant disadvantage. For the production of regenerated cellulose, Baksheev and Butyagin (5) reported a decrease in the world production of cellulose fibers in 1997. However, viscose fiber production and consumption has increased in a larger increment than forecasted. Cellulose fibers, mainly rayon, produced by the viscose process play an important role in textile industries. In addition, it is also used in feminine hygiene products, baby wipes, computer disk liners and surgical swabs (6).

This chapter will focus on the optimization of regenerated cellulose for the conventional viscose process.

\section{Cellulose Structure in Different Levels}

Cellulose is the main component of plant cell walls (7). The content of cellulose in wood varies according to tree species, growing conditions and age; however, most wood species are composed of $40-47 \%$ cellulose, and non-wood plant species contain $60-70 \%$. One of the purest sources of cellulose that can be found in nature is cotton, which consists of more than $95 \%$ cellulose $(8)$.

Cellulose has many interesting properties, including high strength, water insolubility, resistance towards chemical derivatization, and a remarkable efficiency of interaction with aromatic compounds (7). These properties make cellulose valuable for many applications. For many applications, such as paper, textiles, pharmaceuticals, membranes, polymers, and paints, cellulose must be isolated from accompanying raw materials, and for some products it has to be 
converted into derivatives. Nevertheless, there are several obstacles arising from cellulose's structure that hinder these processes due to the limited accessibility and reactivity of native cellulose (9).

The structure of cellulose is complex and has not yet been completely elucidated. Generally, this structure can be considered from three levels: the molecular level, the supramolecular level, and the morphological level.

Cellulose consists of straight and non-branched polymer chains (Figure 1). The average degree of polymerization (DP) of a cellulose molecule is approximately 10.000 in natural wood and 15.000 in cotton (10).

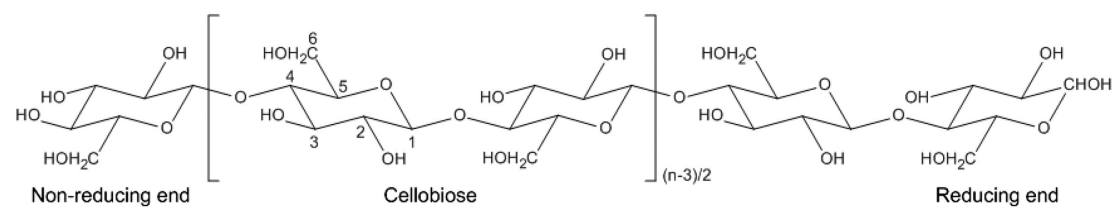

Figure 1. Cellulose structure at the molecular level.

Each glucose unit in a cellulose molecule has the chair formation ${ }^{4} \mathrm{C}_{1}$ and contains three hydroxyl groups in equatorial positions that form intramolecular hydrogen bonds that are responsible for its high rigidity. At the supramolecular level, the intermolecular bonds are constructed between adjoining cellulose molecules, which gives cellulose its insolubility in water and its stable conformation. Consequently, aggregated molecules are assembled through hydrogen bonds, covalent bonds, and van der Waals forces into microfibrils containing the crystalline regions (11). However, cellulose consists not only of highly-ordered crystallites, but also of more disturbed regions with a lower degree of order (amorphous or non-crystalline cellulose). Moreover, the crystalline and amorphous states are not the only two possible states of order; there are also other structures, such as intermediate or para-crystalline states $(12,13)$.

Different polymorphs of cellulose have been identified (cellulose I $\alpha$, I $\beta$, II, $\mathrm{III}_{\mathrm{I}}, \mathrm{IIII}_{\mathrm{II}}, \mathrm{IV}_{\mathrm{I}}$, and $\mathrm{IV}_{\mathrm{II}}$ ) with the help of analytical techniques, such as ${ }^{13} \mathrm{C}$ cross polarization/magic angle spinning nuclear magnetic resonance $\left({ }^{13} \mathrm{C} \mathrm{CP} / \mathrm{MAS}\right.$ NMR), infrared spectroscopy (IR), and diffraction analysis $(14,15)$. These polymorphs present different physical properties, such as density, solubility, and optical properties (7).

Generally, cellulose I is the native form of cellulose, and this polymorph can be converted into cellulose II by either regeneration or mercerization with concentrated alkaline solutions. Cellulose I $\alpha$ is normally found in primitive organisms, such as bacteria and algae, while cellulose I $\beta$ is produced in higher plants, such as cotton and wood. Cellulose I $\alpha$ and cellulose I $\beta$ have different hydrogen bonding patterns. Moreover, cellulose I $\alpha$ has been reported to have higher reactivity in comparison with cellulose I $\beta$. (11).

Cellulose II can be generated from cellulose I by either mercerization or regeneration. In the process of mercerization, cellulose is first submitted to alkalization, where it swells in a strong alkali solution $(18 \% \mathrm{NaOH})$. In this 
step, the strong inter- and intramolecular bonds among cellulose molecules are partially broken and alkali cellulose is produced. This process is terminated by neutralization to remove the alkali and generate cellulose II. Additionally, cellulose can also be regenerated from various solutions, such as acids, chelating agents, organic solvents, and ionic liquids, to generate cellulose II. The method of regeneration was described to exhibit higher efficiency in the conversion of cellulose I to cellulose II when compared with the mercerization method (16).

In addition to crystalline cellulose, less ordered or non-crystalline cellulose is also of great interest $(12,13)$. A two-phase model of cellulose (highly ordered and less ordered regions) was developed in the late 1950s, and the theory was supported by X-ray diffraction patterns $(17,18)$. In 1982, it was discovered that solid state ${ }^{13} \mathrm{C}$ CP/MAS NMR can comprehensively elucidate the cellulose crystallinities of different samples (19).

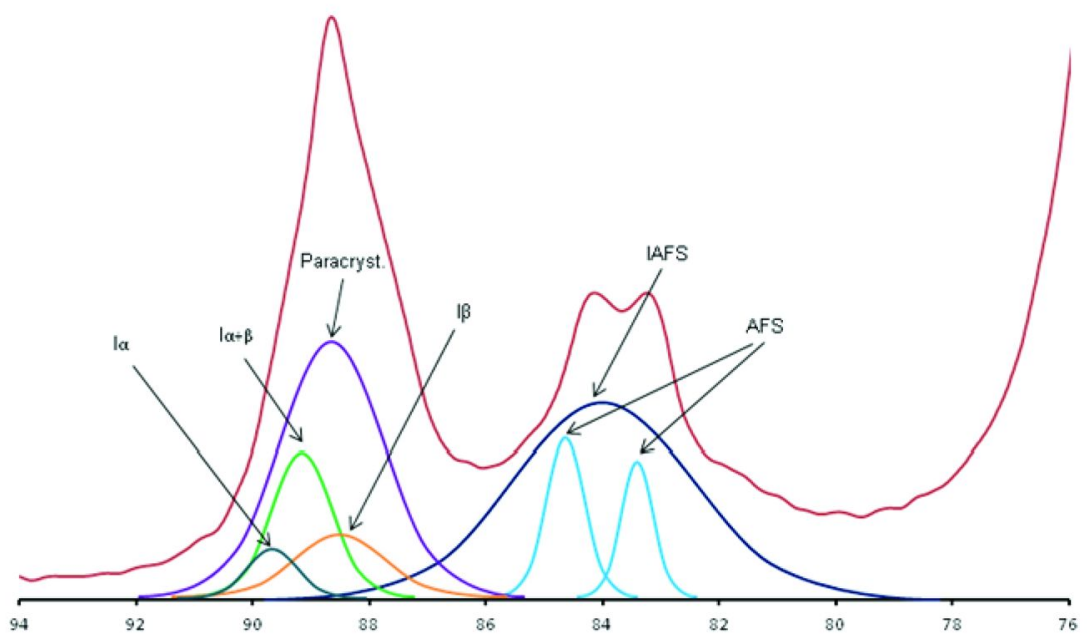

Figure 2. The deconvolution of ${ }^{13} \mathrm{C} C P / M A S$ NMR spectra of cellulose I in the C4 region with Paracryst. $=$ paracrystalline cellulose, IAFS=inaccessible fibril surfaces, $A F S=$ accessible fibril surfaces. (Reproduced with permission from reference (12). Copyright 1997.)

The complicated structure of cellulose results in high analytical complexity. For example, the ${ }^{13} \mathrm{C} \mathrm{CP} / \mathrm{MAS}$ NMR spectrum is very intricate due to overlapping signals that belong to different conformations. For this reason, a deconvolution method was developed to separate and elucidate those signals in the $\mathrm{C} 4$ region of the spectra (Figure 2) so that the different cellulose forms found in the fibril could be quantified.

In the analysis of cellulose morphology with X-ray diffraction, light areas in the diffractogram were attributed to crystalline cellulose and dark areas were attributed to non-crystalline cellulose (20). However, to date, it remains difficult to define the limit between crystalline and non-crystalline cellulose due to the additional occurrence of paracrystallinity, shown by Larsson's and Wickholm's 
models, where the fibrils were thought to be uniform (Figure 3). It is worth to mention that these models are different from Hearle's, which is a structure model containing non-uniform fringed fibrils and more voluminous non-crystalline regions (17).

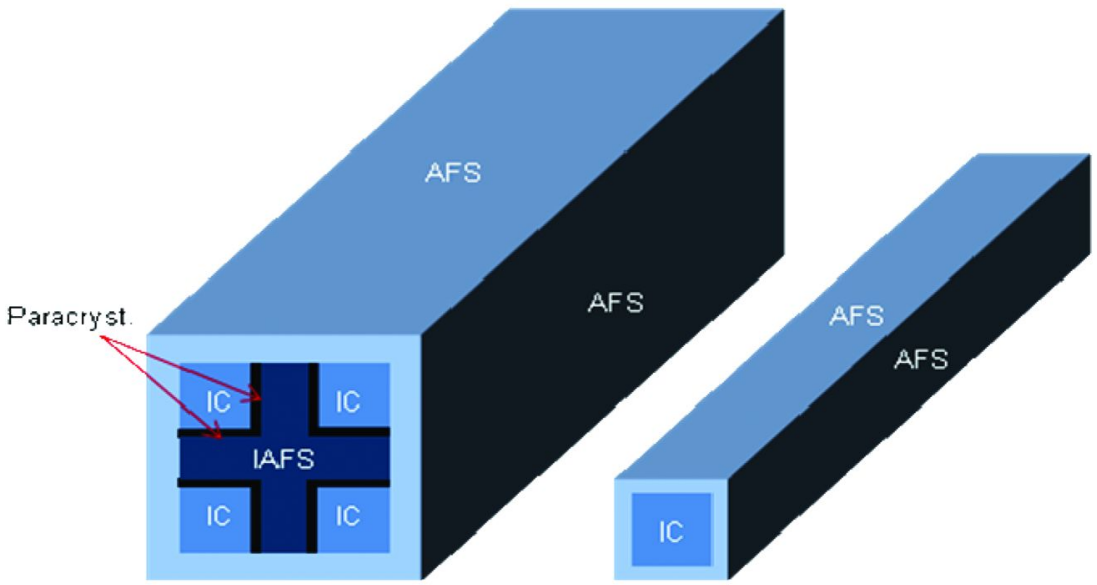

Figure 3. The model for the fibril aggregates (left) and cellulose fibrils (right) with IC=inner crystalline cellulose, Paracryst. = paracrystalline cellulose, $I A F S=$ inaccessible fibril surfaces, $A F S=$ accessible fibril surfaces. (Reproduced with permission from reference (12). Copyright 1997.)

\section{Cellulose Accessibility and Reactivity}

As mentioned above, due to the compact and complex structure of cellulose, its accessibility to chemicals and solvents is restricted. In fact, Krässig (21) has demonstrated that the accessibility and reactivity of cellulose depend strongly on the cellulose structure and morphology. Fahmy and Mobarak (22) also suggested that cellulose reactivity depends more on the disintegration of fibril aggregates than on crystallinity.

The arrangement of cellulose chains in fibrils and fibril aggregates is not uniform, and this creates two morphologically different regions from the superfibrillar level point of view, including highly ordered (crystalline) and less ordered (semi-crystalline or even amorphous) regions. It has been suggested that the less ordered cellulose regions tend to be located on the fibril surface or on the amorphous position in fibrils (12). The accessibility of crystalline cellulose to chemicals or other reagents is limited. The ordered regions with high crystallinity that are packed tightly together in fibrils and aggregates are normally hard to access, while the less ordered or amorphous regions located on fibril surfaces can be reached more readily (23).

In both native and artificial cellulose, the random arrangement of cellulose fibrils creates differences in size and amount of free volume elements throughout the network, which also defines the accessibility of cellulose. Moreover, the accessibility of cellulose is affected by the size of the chemicals and reagents (24). 
Larger biological reagents, such as enzymes, might be blocked from reaching the fibrils due to their size (25). In addition to the structure of cellulose (at the molecular level), the number of accessible hydroxyl groups also affects cellulose's overall accessibility. Consequently, expansion of pores or spaces among cellulose fibrils and the modification of cellulose structures to expose more reachable regions and functional groups are of great importance in increasing cellulose's accessibility $(21)$.

Previous studies have reported several ways of increasing cellulose's accessibility and reactivity. These techniques have focused mainly on chemical degradation (such as hydrolysis and oxidation of raw materials), thermal degradation, mechanical treatments (such as wet/dry milling), and on the swelling of cellulosic materials through the breakage of interfibrillar and intrafibrillar bonds to expose more active surface areas (21). The mixing of cellulose and sodium hydroxide to form alkali cellulose is a typical example of water-based swelling techniques (26). Kunze and Fink (27) described another method based on the combination of sodium hydroxide and urea. One promising method in development uses a relatively new family of solvents, ionic liquids, to increase cellulose's accessibility and reactivity by reassembling cellulose's inner structure (28). In addition, the enzymatic treatment of various cellulose materials has recently gained increased attention. Köpcke et al. reported the use of mono-component endoglucanases to increase the reactivity of various paper-grade and dissolving grade pulps (9). This method of improving cellulose's accessibility and reactivity has clear advantages because enzymes are selective, non-toxic and environmentally friendly.

However, the improvement of the cellulose's accessibility and reactivity may be negatively affected by the hornification effect, especially for dried cellulose materials such as pulp sheets (25). Hornification is caused by the removal of water during the drying of cellulose, causing the formation of new hydrogen bonds between the fibrils and an irreversible shrinking of internal space. This results in decrease of pore size and conversion of accessible regions of the structure into inaccessible ones $(29,30)$. The existence of hemicelluloses in cellulose-based materials may help to reduce hornification (31). Nevertheless, for certain production needs, such as the manufacture of dissolving grade pulps, hemicelluloses must be substantially decreased or totally removed. In this case, hornification becomes a significant issue.

\section{Enzymes Used for Activation of Cellulose}

The increased application of enzymes in various industries is stimulated by the need to decrease environmental impacts. Enzymes present many advantages, such as high performance, high selectivity on substrates, and little to no toxicity compared with conventional chemical reagents.

Enzymes can be used to improve cellulose's accessibility (25). These enzymes include cellulases and hemicellulases. Under certain conditions, cellulases catalyze the hydrolysis of the 1-4-glucosidic bond between two adjacent glucose 
units. These cellulases include endoglucanases (EC.3.2.1.4), cellobiohydrolases or exoglucanases (EC. 3.2.1.91), and glucosidases (EC.3.2.1.21) (Figure 4).

Endoglucanases (EG) are a type of enzyme that catalyzes the random hydrolysis of glucosidic bonds in cellulose chains in the less ordered or amorphous regions, generating shorter chains with lower degrees of polymerization or even oligosaccharides. Among these EGs, the endoglucanase derived from Humicola insolens has been reported to be the most active toward many cellulose derivatives, as it reacts specifically with cellulose and prefers to attack the amorphous region $(32,33)$. Engström et al. (34), Henriksson et al. (35) and Ibarra et al. (36) have reported the high efficiency of this enzyme in improving the cellulose reactivity of dissolving pulps. In the same way, Ibarra et al. $(25,37)$, Köpcke et al. (38-40), Li (41), and Najar (42) have used both mono-component endoglucanase and xylanase enzymes together with alkaline treatments to improve the cellulose reactivity of several raw materials, including both wood and non-wood paper-grade pulps. The potential of converting paper-grade pulps into dissolving grade pulps for viscose processes was also described in these studies.

The catalysis reaction of exoglucanase, however, occurs at the reducing and non-reducing ends of cellulose chains through the so-called "peeling" mechanism. It has been reported that this type of cellulase can also degrade microcrystalline cellulose (43). The product from the hydrolysis is mainly cellobiose, which can be further hydrolyzed into glucose units with the help of glucosidase (44). Cellulases can be used individually or cooperatively with other enzymes for different needs.

The catalytic domain determines the catalyst function of cellulases. Differences in shape among the catalytic domains distinguish cellulases and give them specific properties. The "cleft-shaped" hydrolysis functional region is specific for endoglucanases, while exoglucanases have a "tunnel-shaped" domain that helps them react with the ends of cellulose molecules. Some cellulases possess a second domain, called the cellulose-binding domain (CBD), which works as a "hand" to catch the substrate, thereby facilitating binding to the cellulose molecules. Ibarra et al. have reported that endoglucanases with CBDs are the most effective endoglucanase enzymes for increasing cellulose's reactivity (36). The catalytic domain and the cellulose-binding domain are connected through an inter-domain linker (45).

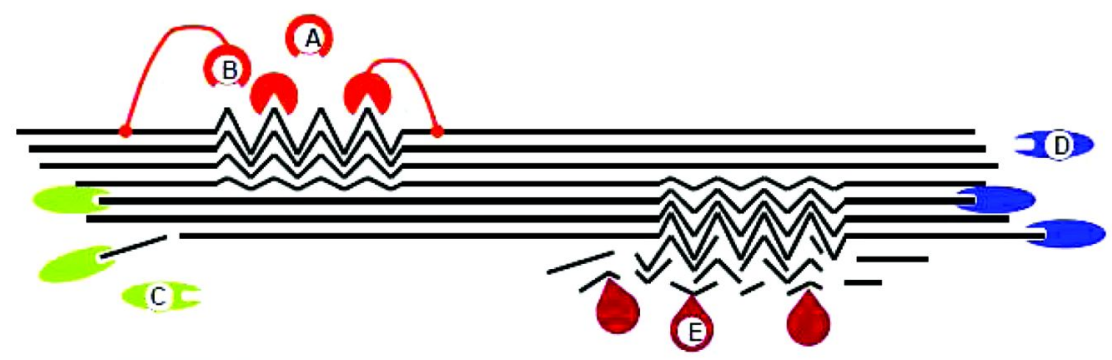

Figure 4. Types of cellulases: A: endoglucanases without cellulose-binding domain; B: endoglucanases with cellulose-binding domain; $C$ and D: cellobiohydrolases. E: glucosidases. 
The mechanism of the activation of cellulose by enzymes has yet to be fully elucidated. One hypothesis states that endoglucanase-catalyzed hydrolysis causes breakage of glucosidic bonds in less ordered regions, which are located between and on the surface of fibrils. This process enhances the separation of the fibrils from one another, increasing the inner space between them. Consequently, the accessible areas of cellulose are available for the reaction with chemicals and other reagents, improving cellulose's reactivity (35). Nevertheless, the effects of hydrolysis are influenced by other factors, such as the crystallinity, the specific surface area and the degree of polymerization of cellulose (46).

In enzymatic treatments, the incubation time, temperature, and $\mathrm{pH}$ value are three parameters that directly affect the improvement of cellulose's accessibility and reactivity. It is difficult to find the most suitable conditions for certain types of enzymes with a particular substrate to obtain the best performance (25, 36-42). It is notable that for different types of substrates and sizes of cellulases, the efficiency of their function may be different. It has been described, for example, that cellulose reactivity could be improved to only a certain level with an endoglucanase treatment. Beyond this level, the reactivity could not be further improved, irrespective of how the conditions and doses of enzymes were changed. Ibarra et al. (25) demonstrated that the existence of higher content of hemicelluloses in raw materials negatively affected the efficiency of endoglucanases, as they might work as a barrier to hinder the enzyme's ability to connect with the accessible cellulose substrates.

To increase cellulose reactivity, xylanases are used to catalyze the hydrolysis of long xylan chains into shorter chains. Köpcke et al. (38) reported the usage of an endoxylanase from a genetically modified Bacillus species in combination with an endoglucanase for the treatment of wood pulps. The results showed that the xylanase worked effectively to remove the xylan that may block the reaction between endoglucanase and cellulose, significantly improving cellulose's reactivity. However, it is worth noting that the size of pores among fibrils and the portion of accessible areas of hemicellulose may influence the function of xylanases through a mechanism similar to that which was previously described for cellulases (25).

\section{Reactivity Measurements}

The reactivity of cellulose is theoretically dominated by the three reactive hydroxyl groups (C2, C3, C6) of each glucose unit (9). However, as mentioned above, cellulose reactivity depends highly on the accessibility of the cellulose. There are several methods that can be used to determine cellulose reactivity. Among them, the Fock method (47) is usually applied (25, 36-42) for determining reactivity for fibers to be used in the viscose process. This method is a lab-scale simulation of the viscose process that uses cellulose in the reaction with carbon disulfide after swelling in sodium hydroxide solution. The dissolved cellulose is then regenerated with diluted sulfuric acid and oxidized by concentrated sulfuric acid and potassium dichromate. The reactivity of cellulose (in percentage) is calculated by measuring the amount of thiosulfate used to titrate the iodine 
formed by the oxidation of iodide with the remaining dichromate. In addition, there are several other methods that are commonly used for the determination of cellulose reactivity. Hopner et al. introduced the oldest method, determination of the water retention value, in 1955 (48), and Nelson et al. (49) reported a method called "iodine sorption analysis" in 1970. Spectroscopic methods, such as FT Raman spectroscopy and ${ }^{31} \mathrm{P}$ NMR spectroscopy, can also be applied for the measurement of reactivity $(50,51)$. In 2002, Christoffersson et al. reported a method of determination that is carried out by calculating the viscose filter value (52).

\section{Dissolving Grade Pulp}

Unlike paper-grade pulp, dissolving grade pulp has a low amount of hemicelluloses, lignin, extractives and minerals (less than $10 \%$ in total) and contains much higher amounts of cellulose (over 90\%). In addition, compared with paper pulp, dissolving pulp exhibits higher brightness and more uniform molecular weight distributions. The high cellulose content of dissolving pulp makes it suitable for the manufacture of regenerated celluloses, such as rayon, and for cellulose derivatives.

Acidic sulfite pulping and prehydrolysis kraft pulping are the main processes used for manufacturing dissolving grade pulp. The former is applied in approximately $65 \%$ of the total production and the latter takes approximately $25 \%$ of the production worldwide (53). Organosolv pulping is another promising method for the manufacture of dissolving pulps, and it has been reported to be more environmentally friendly because the process is sulfur-free, producing dissolving pulp with higher strengths than that produced by conventional techniques. However, the high expenses and low reactivity of some product celluloses limit the generalization of organosolv pulping into larger production $(54,55)$.

To produce regenerated cellulose and cellulose derivatives, one of the most important parameters of dissolving pulp is the processability, which is characterized by cellulose reactivity. High reactivity helps to lower the demand for processing chemicals during both the derivation and the regeneration of cellulose, reducing environmental impact. More importantly, it ensures the homogeneity and quality of final products (37). As mentioned above, cellulose reactivity depends on its accessibility to chemicals, where the accessibility is affected by several factors, including the content of hemicelluloses. Therefore, a dissolving pulp should maintain low levels of hemicelluloses $(2-4 \%)$. The presence of hemicelluloses decreases the cellulose processability, especially during xanthation in the viscose process, affecting the quality of the end products (56). However, the concept that hemicelluloses are impurities and must be removed causes, as a consequence, a relatively low yield compared to common kraft pulping, making the manufacture of these pulps a costly process (57).

Concerning the reactivity, it has been reported that the commercially available (dried) hardwood and softwood dissolving pulps possess cellulose reactivities, according to the Fock method, of $65 \%$ and $70 \%$, respectively (36). 
Henriksson et al., Engström et al., and Ibarra et al. have reported the activation of commercial dissolving pulp through enzymatic treatment by a CBD-containing mono-component endoglucanase. Ibarra et al. has demonstrated that the reactivity of both hardwood and softwood dissolving pulp could reach $85 \%$ according to the Fock method after treatment with a relatively low dose of $30 \mathrm{ECU} / \mathrm{g}$ (ECU: endocellulase units - one unit of endocellulase is defined as the amount of enzyme needed to release $1 \mu \mathrm{mol}$ of glucose per min under the given reaction conditions). This result would be a consequence of the swelling of cellulose fibrils and the reduction of cellulose II (36). Engström et al. have reported that for dissolving pulp that has never been dried, the cellulose reactivity could be elevated to $100 \%$ according to the Fock method with a short reaction time with a lower enzyme dose of $27 \mathrm{ECU} / \mathrm{g}$ (34). The limited accessibility of the dried dissolving pulp compared with the never-dried pulp arises from the hornification effect that was discussed above.

Viscosity is another important parameter to be considered in the production of dissolving pulps, as it can determine the quality of the final product. For example, the viscosity of dissolving pulp should be in the range of $200-300 \mathrm{dm}^{3} / \mathrm{kg}$ to produce viscose rayon of high quality (38). Engström et al. (34) and Ibarra et al. (36) have reported a decrease of viscosity in the dissolving pulp after the endoglucanase treatment. This results from the enzyme helping to cleave the cellulose polymer by catalyzing the hydrolysis of less ordered regions within the fibrils, a theory that is supported by the lower degree of polymerization that was obtained and the relatively smoother surface of cellulose fibers that was observed by scanning electron microscopy (SEM). Moreover, Engström et al., Ibarra et al., and Köpcke et al. have also demonstrated that the increase in cellulose reactivity is not directly related to the decrease in viscosity (38).

\section{The Production of Regenerated Cellulose}

Regenerated cellulose is mainly produced by the viscose process. One of the most important steps during the production of viscose fibers is the formation of cellulose xanthate, in which alkali cellulose reacts with carbon disulfide $\left(\mathrm{CS}_{2}\right)$. To obtain a homogeneous product of high quality, the homogeneity and filterability of the viscose upon regeneration in the acid bath must be ensured. This step, however, depends on the solubility of cellulose xanthate in aqueous sodium hydroxide. An easy way to maximize the solubility of cellulose xanthate is to increase the amount of $\mathrm{CS}_{2}$ in the reaction with alkali cellulose. However, $\mathrm{CS}_{2}$ is a reagent with a well-known and high toxicity in humans and in the environment. It has been reported that the emission of pollutants into the surroundings can arise from $\mathrm{CS}_{2}$ used in many ways during the viscose process (6). For humans, carbon disulfide has been described to be a risk factor for many illnesses (58). As a result, it is important to develop new means to decrease the use of this reagent. One possible way to achieve this goal is to find alternatives that effectively dissolve cellulose, of which the dissolution of cellulose in NMMO is an example. In this process, cellulose is directly dissolved in an NMMO/water mixture and regenerated into 
filaments through spinning. The cellulose filaments produced by this method are called Lyocell fibers. Similar to rayon, Lyocell fiber is mostly used in textiles (2).

High loop tenacity is one of the advantages of Lyocell. More importantly, the production of Lyocell is more environmentally friendly due to the absence of $\mathrm{CS}_{2}$. However, several studies have described problems with this method, including the fibrillation tendency of Lyocell fibers, side reactions and the yellowing of end products caused by chromophores that were generated during production (59). These issues hamper the application of Lyocell fibers in textile industries over the use of viscose rayon (60).

Another alternative is to dissolve cellulose in ionic liquids (ILs). These liquids, containing both cations and anions, are a relatively new family of non-volatile solvents. They are normally found in the liquid state at room temperature because of the low melting temperature (below $100^{\circ} \mathrm{C}$ ). Swatloski et al. (61) have reported that ILs are convenient and inert solvents for lignocellulosic materials. ILs are claimed to be green solvents $(62,63)$. Cellulose dissolved in ILs can be regenerated with common anti-solvents, such as water, ethanol, or acetone, which makes the precipitation and the production of regenerated cellulose in many forms, such as powder, tube, fiber, and film, relatively facile (61). However, several problems of using ILs have been described, as the complete removal of ILs from regenerated cellulose and the control of the DP of the final product remain challenging $(64,65)$.

Consequently, to date, the viscose process continues to dominate the production of regenerated cellulose, leaving the use of $\mathrm{CS}_{2}$ as a cumbersome issue. As discussed above, the accessibility of cellulose to chemicals is limited, especially for paper-grade pulps. Their correspondingly lower accessibility and lower reactivity compared to dissolving pulp makes these pulps difficult to be used as a starting material for producing regenerated cellulose. However, the higher costs arising from dissolving pulp and overcharging of $\mathrm{CS}_{2}$ remain a problem. Thus, to decrease the amount of $\mathrm{CS}_{2}$ needed during the production, to increase quality and homogeneity of the end product, and to save costs, several studies have been conducted to modify cellulose for better accessibility and reactivity, including activation of traditional dissolving grade pulps and upgrading of paper-grade pulps into dissolving grade pulps $(25,36-42)$.

\section{Upgrading Paper-Grade Pulps into Dissolving Grade Pulps}

The conversion of paper-grade pulps into dissolving grade pulps aims at increasing the cellulose's accessibility and reactivity, controlling the DP, and decreasing the amount of hemicelluloses. As mentioned earlier, the low yield resulting from the removal of hemicelluloses and the relatively strict demands on storage and transportation elevate the price of dissolving grade pulp. Consequently, upgrading a relatively cheaper material, such as paper-grade pulps, through a cost-effective and industrially friendly way to meet worldwide production demands has become an attractive topic for researchers pulps (25, $36-42)$. 
Several studies have focused on the modification of carbohydrate compositions in pulps, as hemicelluloses are considered to be impurities in this circumstance. Other studies have tried to develop new methods for controlling carbohydrate composition, including nitren and cuen extraction, alkaline extraction and enzymatic treatments (66-70). Others have worked to change cellulose's structure with chemical treatments. Stephens, for example (71), has reported a method of swelling kraft pulp in aqueous suspensions to decrease the DP of cellulose and increase cellulose's accessibility, upgrading the original material into dissolving pulp.

Other authors have described series of conversions that transform paper-grade pulp from both wood and non-wood materials into dissolving pulp through combined procedures based on alkaline treatment and enzymatic treatment $(25,37-42)$. The effect of these treatments on various paper-grade pulps was determined by measuring the cellulose reactivity according to the Fock method, the pulp viscosity, carbohydrate composition, molecular weight distribution, morphology and supramolecular structure. Based on the use of mono-component endoglucanases as effective reagents to increase the accessibility and reactivity and to decrease the viscosity of both hardwood and softwood dissolving pulps, EGs were used in the conversion of paper-grade pulps to dissolving pulps.

CBD-containing mono-component endoglucanases, such as Novozyme 476 (N476), have shown a strong potential as activating reagents for paper-grade pulps. Two common hardwood paper-grade pulps derived from birch and eucalyptus possess much higher cellulose reactivities according to the Fock method after treatment with N476. Initially, the pulps presented a cellulose reactivity of $40 \%$ and $36 \%$, respectively. After treatment, values of approximately $60 \%$ were observed. In addition, the viscosity decreased significantly from approximately 700 and $800 \mathrm{dm}^{3} / \mathrm{kg}$ to approximately 500 and $700 \mathrm{dm}^{3} / \mathrm{kg}$, respectively (Figure 5), as a result of the cleavage of cellulose chains aided by the endoglucanase. It is also worth noting that the most significant effects occurred at low enzyme doses, approximately $50 \mathrm{ECU} / \mathrm{g}$ dry weight pulp, though further increases were observed up to an enzyme load of $250 \mathrm{ECU} / \mathrm{g}$ dry weight pulp.

For a paper-grade pulp from softwood (a mixture of spruce and pine), a similar trend was observed (Figure 6). The initial cellulose reactivity was elevated from approximately $50 \%$ to above $70 \%$ according to the Fock method, which is close to that of a commercial dissolving pulp (36). The strongest enhancement of reactivity occurred at enzyme doses of approximately $50 \mathrm{ECU} / \mathrm{g}$ dry weight pulp.

The effect of the endoglucanase on non-wood paper-grade pulps was also reported. The behavior of these materials was similar to that of wood pulps, especially for sisal pulps. For this pulp, the cellulose reactivity was significantly improved from $36 \%$ to approximately $60 \%$ by the enzymatic treatment. For other samples, the endoglucanase failed to raise cellulose reactivity to this level. The enzyme did not affect the reactivities of some non-wood pulps, including flax and hemp. The effect on the viscosity, however, was higher for abaca and flax. For the sisal pulp, no significant change in the viscosity was observed (Figure 7). These results imply that there is no direct correlation between the decrease in viscosity and the increase in cellulose reactivity (34). 
-Birch Eucalyptus $n$ CHDP

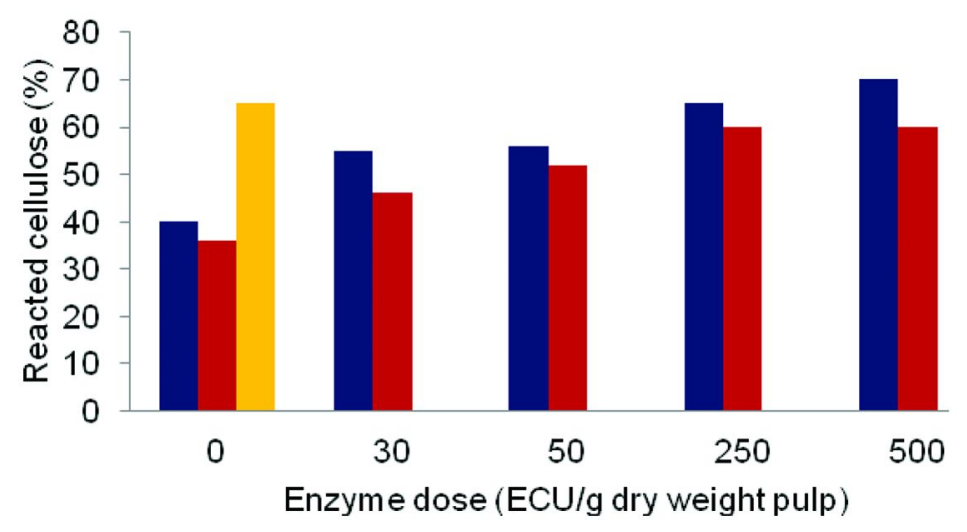

-Birch Eucalyptus CHDP

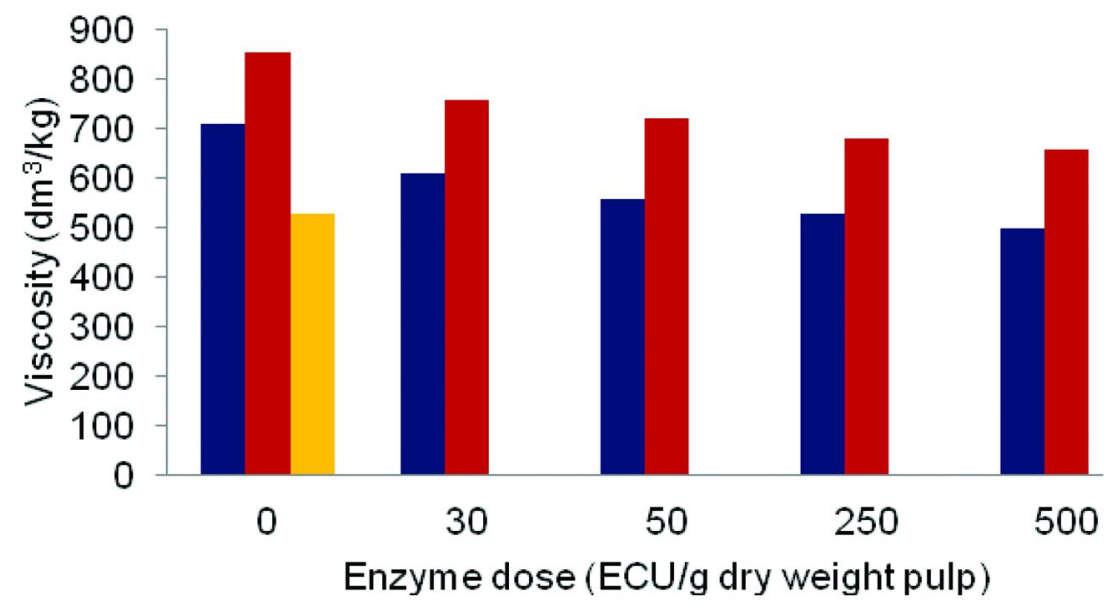

Figure 5. Fock's reactivity (up) and viscosity (down) of birch and eucalyptus paper-grade pulps as a function of enzyme dose and comparison with commercial hardwood dissolving pulp (CHDP). (Reproduced with permission from reference (38). Copyright 2008.) 


\section{-Softwood $n$ CSDP}

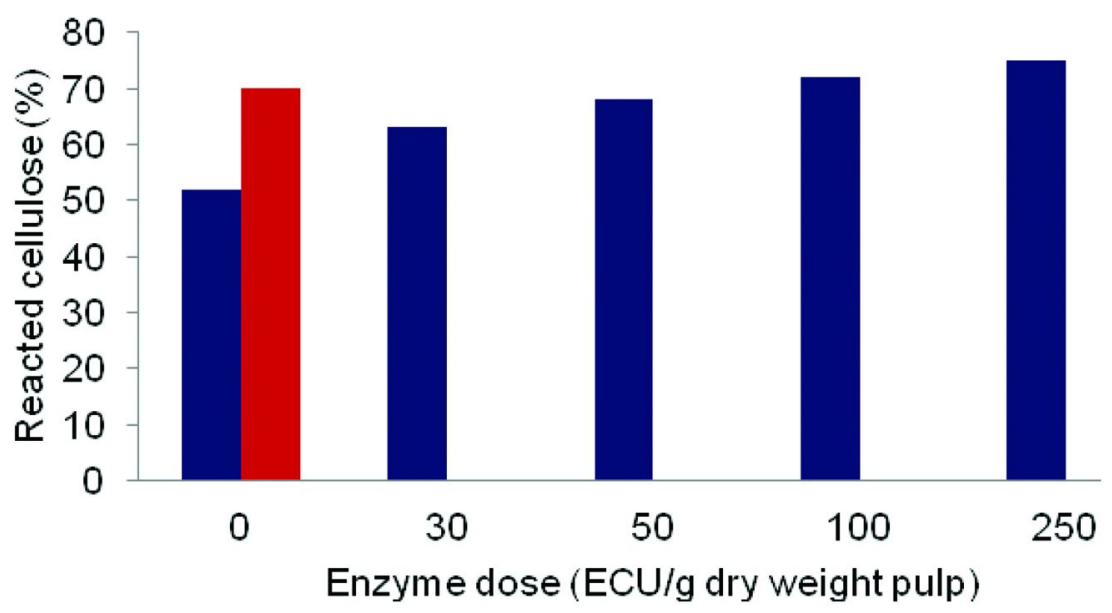

Figure 6. Fock's reactivity of softwood paper-grade pulp as a function of enzyme dose and comparison with commercial softwood dissolving pulp (CSDP).

The reaction time of the enzymatic treatment was also reported to be an important factor that influenced the efficiency of the treatment. For hardwood, softwood, and non-wood paper-grade pulps, the optimal reaction time for endoglucanase treatment was found to be $1 \mathrm{~h}(37,38,41)$.

However, from these studies, the cellulose reactivity of different paper-grade pulps could not be further improved after the enzyme dose reached a certain point. The hemicelluloses that cover or precipitate on the surface of cellulose might limit its accessibility. To further enhance the cellulose reactivity and meet the requirements for use as dissolving grade pulps, the content of hemicelluloses within these paper-grade pulps must be lowered. Hemicellulase treatment is thought to be an effective and selective way for removing hemicelluloses. Köpcke et al. reported several trials using a xylanase treatment on paper-grade pulps from birch, eucalyptus, and sisal $(25,37,38)$. The results showed that the contents of xylan, which was the main hemicellulose in these pulps, all significantly decreased to $13-14 \%$ (based on the carbohydrate analysis result) after treatment using an enzyme dose of $500 \mathrm{EXU} / \mathrm{g}$ of dry weight pulp (EXU: endoxylanase units - one unit of endoxylanase is defined as the needed amount of enzyme to release $1 \mu \mathrm{mol}$ of xylose per min under the given reaction conditions). The xylan content, however, could not be further decreased even with higher doses of xylanase. This was explained by the limited accessibility of the residual xylan and the size of xylanase itself (72). 


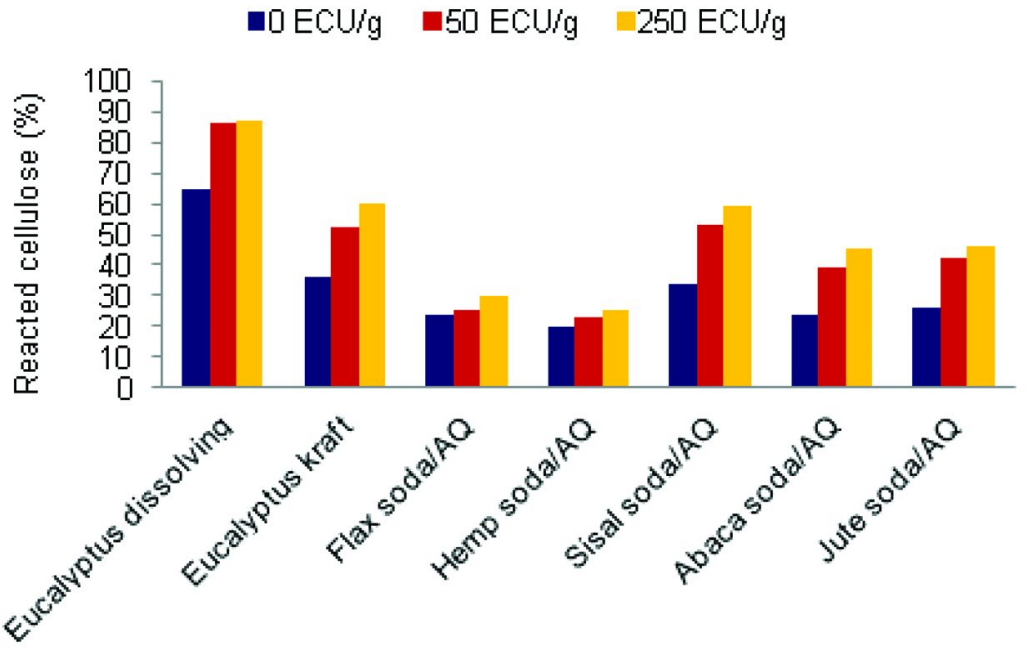

$-0 \mathrm{ECU} / \mathrm{g} \quad-50 \mathrm{ECU} / \mathrm{g} \quad 250 \mathrm{ECU} / \mathrm{g}$

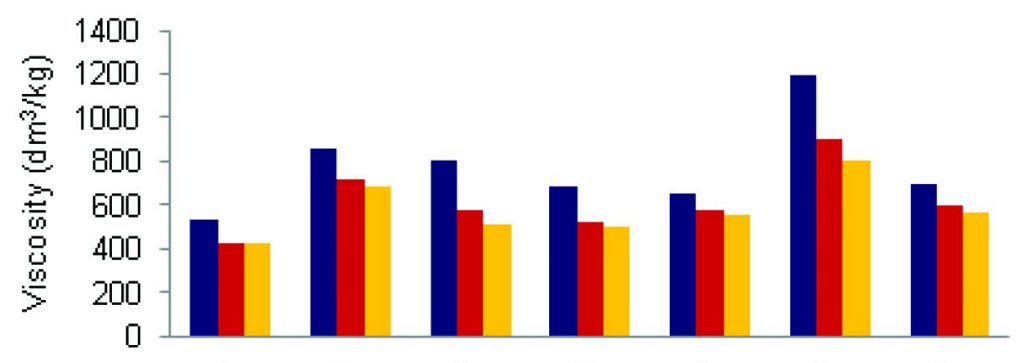

Figure 7. Fock's reactivity (up) and viscosity (down) of different endoglucanase-treated wood and non-wood pulp compared with eucalyptus dissolving pulp. ECU/g: endocellulase units per gram of dry pulp. (Reproduced with permission from reference (37). Copyright 2010.)

Commercial dissolving grade pulps require the content of hemicelluloses to be lower than $10 \%(9)$. Paper grade pulps treated only with xylanase could not meet this requirement. As a result, alkali treatment, a less selective (this treatment hydrolyzes cellulose as well) but cheaper and very effective method can be applied to these paper-grade pulps to further remove hemicelluloses. Several studies have described trials of alkali treatments on paper-grade pulps $(25,37$, 
$39,40,42)$. The treatments were carried out with an alkaline loading of $9 \mathrm{wt} \%$. Ibarra et al. and Köpcke et al. demonstrated that the content of xylan was further decreased to a value of approximately 5\% after the treatment. However, the cellulose reactivity also decreased as a result of hornification after drying. As discussed earlier, hornification can be hindered by the presence of hemicelluloses (73). After removing the majority of the xylan, hornification might occur more easily and might therefore lower the accessibility and reactivity of cellulose. These authors tried to solve this problem by combining xylananase, alkali, and endoglucanase treatments and testing several sequences of modification $(25,37$, $39,40,42$ ). Because the most suitable condition for xylanase treatment (dose: 500 EXU/g dry weight pulp, incubation time: $2 \mathrm{~h}$, temperature: $60^{\circ} \mathrm{C}$ ) was already established, optimizing the sequence of treatments on different pulps started by determining the best conditions for alkali treatment to remove the maximum amount of hemicelluloses. The alkaline load was reported be most effective at $7 \%$, as the formation of cellulose II was detected by ${ }^{13} \mathrm{C} \mathrm{CP} / \mathrm{MAS}$ NMR if the pulps were treated with higher alkaline concentrations $(9 \%)$. The amount of hemicelluloses could be limited to below $10 \%$. In addition, the best reaction time of alkali treatment was reported to be $10 \mathrm{~min}(9)$. As with the endoglucanase treatment, the most favorable enzyme dose was found to be $250 \mathrm{ECU} / \mathrm{g}$ of dry weight pulp, and the most suitable incubation time and temperature were $1 \mathrm{~h}$ and $50^{\circ} \mathrm{C}$, respectively $(9)$.

The optimized sequences of combined treatment on birch, eucalyptus, and sisal soda/AQ pulps were reported to be different. The best modification sequence for birch pulp was two series of alkali treatments followed by the endoglucanase treatment, with the most favorable conditions as discussed above. In contrast, for eucalyptus and sisal soda/AQ pulps, the best sequence was a xylanase treatment prior to alkali extraction and then an endoglucanase treatment as the last step. The changes in these sequences were based on the evaluation of carbohydrate composition, reactivity of cellulose, and viscosity (Table 1 and 2), where reactivity was primarily considered. The xylanase treatment together with the alkali extraction could fulfill the requirements for the upgraded paper-grade pulps to be used as dissolving grade pulps in terms of their hemicellulose content. The addition of the endoglucanse treatment as the last step was of great importance to achieve high cellulose reactivity. It was also observed that the endoglucanase treatment prevented hornification effects produced by the removal of hemicellulose. This was explained by the hypothesis that the short cellulose chains created by hydrolysis possibly precipitated onto the pores that were generated after removal of hemicelluloses from the previous steps. This effect may hinder the formation of new hydrogen bonds, which causes the cellulose fibrils to be farther apart and therefore limits the hornification effects (38). Although the upgraded paper-grade pulps had lower viscosity than the commercial dissolving pulp $\left(530 \mathrm{dm}^{3} / \mathrm{kg}\right)$, the value was still acceptable. During the viscose process, the viscosity of the original dissolving pulp normally decreases to $160-200 \mathrm{dm}^{3} / \mathrm{kg}$ to give better filterability (9). This part of the process takes a significant period of time $(0.5-5 \mathrm{~h})$. The upgraded pulps, with a viscosity of approximately $200-300 \mathrm{dm}^{3} / \mathrm{kg}$, could avoid this step and still meet the needs for the manufacture of cellulose products of high quality (36). 
Table 1. Carbohydrate composition (glucose and xylose) of eucalyptus, birch and sisal soda/AQ paper pulps after different sequences of treatments ${ }^{a}$

\begin{tabular}{|c|c|c|c|c|c|c|c|c|}
\hline \multirow[b]{2}{*}{ Treatment } & \multicolumn{2}{|c|}{$\begin{array}{c}\text { Commercial } \\
\text { eucalyptus } \\
\text { dissolving } \\
\text { pulp }\end{array}$} & \multicolumn{2}{|c|}{ Eucalyptus } & \multicolumn{2}{|c|}{ Birch } & \multicolumn{2}{|c|}{$\begin{array}{c}\text { Sisal } \\
\text { soda/AQ }\end{array}$} \\
\hline & $\begin{array}{l}\text { Glu } \\
(\%)\end{array}$ & $\begin{array}{l}X y l \\
(\%)\end{array}$ & $\begin{array}{l}\text { Glu } \\
(\%)\end{array}$ & $\begin{array}{l}X y l \\
(\%)\end{array}$ & $\begin{array}{l}\text { Glu } \\
(\%)\end{array}$ & $\begin{array}{l}X y l \\
(\%)\end{array}$ & $\begin{array}{l}\text { Glu } \\
(\%)\end{array}$ & $\begin{array}{l}X y l \\
(\%)\end{array}$ \\
\hline N/A & 97.6 & 2.4 & 81.7 & 18.3 & 73.4 & 25.5 & 81.0 & 18.1 \\
\hline $\mathrm{X}+\mathrm{AE}$ & N/A & N/A & N/A & N/A & N/A & N/A & 95.6 & 3.6 \\
\hline $\mathrm{X}+\mathrm{EG}$ & N/A & N/A & N/A & N/A & N/A & N/A & 85.0 & 14.2 \\
\hline $\mathrm{X}+\mathrm{AE}+\mathrm{EG}$ & N/A & N/A & 94.4 & 4.8 & 94.5 & 4.6 & 95.5 & 3.9 \\
\hline $\mathrm{AE}+\mathrm{AE}+\mathrm{EG}$ & N/A & N/A & 94.5 & 4.8 & 92.2 & 5.5 & N/A & N/A \\
\hline $\mathrm{AE}+\mathrm{AE}+\mathrm{AE}+\mathrm{EG}$ & N/A & N/A & 95.2 & 4.2 & 94.1 & 4.4 & N/A & N/A \\
\hline
\end{tabular}

a X: xylanase treatment (500 EXU/g dry weight pulp, $2 \mathrm{~h}, 60^{\circ} \mathrm{C}$; EXU: endoxylanase units); AE: alkali treatment $\left(7 \% \mathrm{NaOH}, 10 \mathrm{~min}, 20^{\circ} \mathrm{C}\right.$ for wood pulps; $9 \% \mathrm{NaOH}, 1 \mathrm{~h}$, room temperature for sisal soda/AQ pulp); EG: endoglucanase treatment (250 ECU/g dry weight pulp, $1 \mathrm{~h}, 50^{\circ} \mathrm{C}$; ECU: endocellulase units); N/A: data are not available.

Table 2. Fock's reactivity (R) and viscosity (V) of eucalyptus, birch and sisal soda/AQ paper pulps after different sequences of treatments ${ }^{a}$

\begin{tabular}{|c|c|c|c|c|c|c|c|c|}
\hline \multirow[b]{2}{*}{ Treatment } & \multicolumn{2}{|c|}{$\begin{array}{c}\text { Commercial } \\
\text { eucalyptus } \\
\text { dissolving } \\
\text { pulp }\end{array}$} & \multicolumn{2}{|c|}{ Eucalyptus } & \multicolumn{2}{|c|}{ Birch } & \multicolumn{2}{|c|}{ Sisal soda/AQ } \\
\hline & $\begin{array}{c}R \\
(\%)\end{array}$ & $\begin{array}{c}V \\
\left(d m^{3} /\right. \\
k g)\end{array}$ & $\begin{array}{c}R \\
(\%)\end{array}$ & $\begin{array}{c}V \\
\left(d m^{3} /\right. \\
k g)\end{array}$ & $\begin{array}{c}R \\
(\%)\end{array}$ & $\begin{array}{c}V \\
\left(\mathrm{dm}^{3} /\right. \\
\mathrm{kg})\end{array}$ & $\begin{array}{c}R \\
(\%)\end{array}$ & $\begin{array}{c}V \\
\left(\mathrm{dm}^{3} /\right. \\
\mathrm{kg})\end{array}$ \\
\hline N/A & 64.8 & 530 & 36.1 & 855 & 40 & 712 & 34.8 & 655 \\
\hline $\mathrm{X}+\mathrm{AE}$ & N/A & N/A & N/A & N/A & N/A & N/A & 31.1 & 725 \\
\hline $\mathrm{X}+\mathrm{EG}$ & N/A & N/A & N/A & N/A & N/A & N/A & 65.4 & 440 \\
\hline $\mathrm{X}+\mathrm{AE}+\mathrm{EG}$ & N/A & N/A & 67 & 335 & 68 & 370 & 66.2 & 290 \\
\hline $\mathrm{AE}+\mathrm{AE}+\mathrm{EG}$ & N/A & N/A & 58 & 330 & 69 & 330 & N/A & N/A \\
\hline $\mathrm{AE}+\mathrm{AE}+\mathrm{AE}+\mathrm{EG}$ & N/A & N/A & 40 & 300 & 60 & 285 & N/A & N/A \\
\hline
\end{tabular}

a X: xylanase treatment (500 EXU/g dry weight pulp, $2 \mathrm{~h}, 60^{\circ} \mathrm{C}$; EXU: endoxylanase units); AE: alkali treatment $\left(7 \% \mathrm{NaOH}, 10 \mathrm{~min}, 20^{\circ} \mathrm{C}\right.$ for wood pulps; $9 \% \mathrm{NaOH}, 1 \mathrm{~h}$, room temperature for sisal soda/AQ pulp); EG: endoglucanase treatment (250 ECU/g dry weight pulp, $1 \mathrm{~h}, 50^{\circ} \mathrm{C}$; ECU: endocellulase units); N/A: data are not available.

183

In Functional Materials from Renewable Sources; Liebner, F., et al.; ACS Symposium Series; American Chemical Society: Washington, DC, 2012. 
The paper-grade pulps from birch, eucalyptus, and sisal after the combined treatments have been shown to exhibit characteristics similar to those of a commercial dissolving grade pulp. The molecular weight distribution (MWD) was analyzed by size exclusion chromatography (Table 3). The treated paper pulps had a lower polydispersity index (PDI) than those of commercial dissolving pulps, which implies that these upgraded pulps have better homogeneity and are suitable for the manufacture of uniform cellulose products (25). The upgraded birch and eucalyptus paper pulps presented proportions of high-molecular weight cellulose (DP>2000) similar to those of commercial dissolving pulps, which suggests the possibility of using these upgraded paper pulps in manufacture of cellulose products with high quality (55). Finally, these treated wood and non-wood paper pulps showed relatively lower weight-average degrees of polymerization (DPw) compared to those of commercial dissolving pulp, which might arise from the cleavage of long cellulose molecules by endoglucanase (25).

Table 3. Comparison of molecular weight distribution among birch, eucalyptus, and sisal soda/AQ paper pulps, upgraded pulps, and commercial eucalyptus dissolving pulpa. Adapted from permission from references $(25$, 37, 39, 40). Copyright 2009, 2010, 2010, 2010.

\begin{tabular}{|c|c|c|c|c|c|}
\hline Pulp & $D P w$ & $P D I$ & $\begin{array}{c}D P<50 \\
\quad(\%)\end{array}$ & $\begin{array}{c}D P<200 \\
\quad(\%)\end{array}$ & $\begin{array}{c}D P>2000 \\
(\%)\end{array}$ \\
\hline $\begin{array}{l}\text { Commercial } \\
\text { eucalyptus dissolving } \\
\text { pulp }\end{array}$ & 2390 & 7.4 & 7.9 & 15.9 & 26.8 \\
\hline Birch kraft pulp & 6213 & 27.9 & N/A & N/A & N/A \\
\hline $\begin{array}{l}\mathrm{AE}+\mathrm{AE}+\mathrm{EG} \text { treated } \\
\text { birch pulp }\end{array}$ & 1733 & 4.5 & 4.8 & 17.7 & 21.5 \\
\hline Eucalyptus kraft pulp & 6055 & 20.5 & N/A & N/A & N/A \\
\hline $\begin{array}{l}\mathrm{X}+\mathrm{AE}+\mathrm{EG} \text { treated } \\
\text { eucalyptus pulp }\end{array}$ & 1545 & 7.4 & 4.9 & 13.8 & 21.2 \\
\hline Sisal soda/AQ pulp & 3575 & 9.6 & $\mathrm{~N} / \mathrm{A}$ & N/A & $\mathrm{N} / \mathrm{A}$ \\
\hline $\begin{array}{l}\mathrm{X}+\mathrm{AE}+\mathrm{EG} \text { treated } \\
\text { sisal pulp }\end{array}$ & 1200 & 5.3 & 3.9 & 17.9 & 14.5 \\
\hline
\end{tabular}

a AE: alkali treatment $\left(7 \% \mathrm{NaOH}, 10 \mathrm{~min}, 20^{\circ} \mathrm{C}\right.$ for wood pulps; $9 \% \mathrm{NaOH}, 1 \mathrm{~h}$, room temperature for sisal soda/AQ pulp); EG: endoglucanase treatment (250 ECU/g dry weight pulp, $1 \mathrm{~h}, 50^{\circ} \mathrm{C}$; ECU: endocellulase units); X: xylanase treatment (500 EXU/g dry weight pulp, $2 \mathrm{~h}, 60^{\circ} \mathrm{C}$; EXU: endoxylanase units); DPw: weight average degree of polymerization; PDI: polydispersity index; N/A: data are not available.

The upgrading of softwood paper-grade pulp has also been described. Li (41) tried sequential treatments on a dried paper-grade pulp from spruce and pine, but only enzymes (xylanase, mannanase, endoglucanase) were applied. The treated pulps exhibited similar characteristics to commercial softwood dissolving grade pulp (Table 4). 
Table 4. Fock's reactivity $(R)$, viscosity (V), and carbohydrate composition

(glucose, xylose, and mannose) of softwood paper pulp after different sequences of treatmentsa

\begin{tabular}{cccccc}
\hline Sample & $R(\%)$ & $V\left(\mathrm{dm}^{3} / \mathrm{kg}\right)$ & Glu (\%) & Xyl (\%) & Man (\%) \\
\hline $\begin{array}{c}\text { Commercial } \\
\text { softwood dissolving } \\
\text { pulp }\end{array}$ & 70 & 560 & 93.0 & N/A & N/A \\
$\begin{array}{c}\text { Softwood paper- } \\
\text { grade pulp }\end{array}$ & 52 & 918 & 85.0 & 8.7 & 6.3 \\
$\begin{array}{c}\text { EG treated softwood } \\
\text { pulp }\end{array}$ & 68 & N/A & N/A & N/A & N/A \\
$\begin{array}{c}\text { EG b treated } \\
\text { softwood pulp }\end{array}$ & 72 & 569 & N/A & N/A & N/A \\
$\begin{array}{c}\text { X+M+EG treated } \\
\text { softwood pulp }\end{array}$ & 80 & 519 & 87.0 & 6.5 & 6.5 \\
$\begin{array}{c}\text { X+M+EG treated } \\
\text { softwood pulp } \\
\begin{array}{c}\text { ME treated } \\
\text { softwood pulp }\end{array}\end{array}$ & 80 & 519 & 87.1 & 6.3 & 6.6 \\
$\begin{array}{c}\text { MEb treated } \\
\text { softwood pulp }\end{array}$ & 73 & 436 & N/A & N/A & N/A \\
\hline
\end{tabular}

a EG: endoglucanase treatment (a: $50 \mathrm{ECU} / \mathrm{g}$ dry weight pulp, b: $100 \mathrm{ECU} / \mathrm{g}$ dry weight pulp, $1 \mathrm{~h}, 50^{\circ} \mathrm{C}$; ECU: endocellulase units); X: xylanase treatment (500 EXU/g dry weight pulp, $2 \mathrm{~h}, 60^{\circ} \mathrm{C}$; EXU: endoxylanase units); M: mannanase treatment (500 VHCU/g dry weight pulp, $2 \mathrm{~h}, 40^{\circ} \mathrm{C}$; VHCU: viscosity hemicellulase units); ME: multi-component enzyme treatment (a: $50 \mathrm{EGU} / \mathrm{g}$ dry weight pulp, b: $100 \mathrm{EGU} / \mathrm{g}$ dry weight pulp, $1 \mathrm{~h}$, $50^{\circ} \mathrm{C}$; EGU: endoglucanase units); N/A: data are not available.

The content of xylan decreased as a result of the xylanase treatment. However, a relatively higher amount of hemicelluloses in the upgraded softwood pulp compared with those in the commercial dissolving pulp was observed. As mentioned above, the efficiency of enzymes depends on the accessibility of the substrate, and enzymes that are larger in size than the pores among the fibrils in pulp might be blocked, and therefore only the accessible hemicelluloses were attacked. Moreover, the content of glucomannan (reflected by mannose here) was not affected by the mannanase treatment, which might be caused by a hindrance effect arising from the arrangement of xylan and glucomannan in this softwood pulp (74). Nevertheless, the sequential treatment succeeded in removing the hemicelluloses to some extent, and the purity of cellulose in the upgraded paper pulp was close to that of the dissolving pulp.

Furthermore, Li described another method of upgrading paper pulp (41). In these experiments, a multi-component enzyme was used as the reagent, which was reported to have various activities as both cellulase and hemicellulase (75). The paper-grade pulp treated by this enzyme showed an obvious increase in its cellulose reactivity and a decrease of viscosity, which could be attributed to the 
synergic function of the multi-component enzyme (Table 4). Moreover, unlike the xylanases and endoglucanases with high enzyme purities (mono-component), the multi-component enzyme has an advantage of being lower in cost.

Finally, for the forest industry, the feasibility of enzymatic treatments on paper-grade pulps depends highly on the economic aspects. Kvarnlöf demonstrated the possibility of decreasing the production cost of viscose fibers by the activation of cellulose materials (dissolving grade pulps) with enzymes in advance (76). The total cost was predicted to be reduced by $3 \%-16 \%$ in comparison with the conventional method, with the consideration of investments on enzymes and corresponding reactors. As to the current method, the lower cost of paper-grade pulps is another advantage from the economical point of view.

\section{Conclusions}

Enzymatic treatments demonstrated a strong potential for the improvement of cellulose accessibility and reactivity and for the conversion of paper-grade pulps to dissolving grade pulps in a selective, effective, and environmentally friendly manner. This method is of great significance for the fabrication of cellulose fibers, especially for viscose manufacturing, where enzymatic treatment could help to reduce the load of carbon disulfide and therefore lower production expenses.

The upgraded pulps from different sources (hardwood, softwood, and sisal) exhibited characteristics similar to those of dissolving pulps. The efficiency of treatments depended on the type of enzymes used, the structure of these enzymes, the reaction conditions, the treatment sequences (in combination with alkali extraction), and the cellulose substrates. However, the feasibility of this method in industry for the large-scale production of pure cellulose has yet to be evaluated.

\section{References}

1. Klemm, D.; Heublein, B.; Fink, H-P.; Bohn, A. Angew. Chem., Int. Ed. 2005, 44, 3358-3393.

2. Shen, L.; Patel, M. K. Lenzinger Ber. 2010, 88, 1-59.

3. Patrick, K. Dissolving Pulp Gold Rush in High Gear. Paper360, September/ October, 2011.

4. Cotton Impact Assessment. Internet Consultation of Stakeholders' View on the EU Cotton Regime: An Overview of the Results; European Commission, 2007.

5. Baksheev, I. P.; Butyagin, P. A. Fiber Chem. 1997, 29 (4).

6. Beach, R. H.; Van Houtven, G. L.; Buckley, M. C.; Depro, B. M. Economic Analysis of Air Pollution Regulations: Miscellaneous Cellulose Manufacturing Industry--Industry Profile; U.S. Environmental Agency, 2000.

7. Henriksson, G.; Lennholm, H. Wood Chemistry and Biotechnology. In Pulp and Paper Chemistry and Technology; Ek, M., Gellerstedt, G., Henriksson, G., Eds.; Walter de Gruyter: Berlin, Germany, 2009; Vol. 1, pp 71-99. 
8. Klemm, D.; Schmauder, H-P.; Heinze, T. Cellulose; Biopolymers Online; Wiley-VCH Varlag: Weinheim, Germany, 2005.

9. Köpcke, V. Ph.D. Thesis, Royal Institute of Technology, Stockholm, Sweden, 2010.

10. Sjöström, E. Wood Chemistry: Fundamentals and Applications, 2nd ed.; Academic Press: San Diego, CA, 1993; p 59.

11. O’Sullivan, A. C. Cellulose 1997, 4, 173-207.

12. Larsson, P. T.; Wickholm, K.; Iversen, T. Carbohydr. Res. 1997, 302, 19-25.

13. Wickholm, K.; Larsson, P. T.; Iversen, T. Carbohydr. Res. 1998, 312, 123-129.

14. Sugiyama, J.; Persson, J.; Chanzy, H. Macromolecules 1991, 24, 2461-2466.

15. Atalla, R. H.; Van der Hart, D. L. In Cellulose and Wood: Chemistry and Technology, Proceedings of the Tenth Cellulose Conference; Schuerch, C., Ed.; John Wiley and Sons: Hoboken, NJ, 1984; pp 169-187.

16. Kolpak, F. J.; Blackwell, J. Macromolecules 1976, 9, 273-278.

17. Hearle, J. W. S. J. Polymer Sci. 1958, 28, 432-435.

18. Zuckerstätter, G.; Schild, G.; Wollboldt, P.; Röder, T.; Weber, H. K.; Sixta, H. Lenzinger Ber. 2009, 87, 38-46.

19. Horii, F.; Hirai, A.; Kitamaru, R. Polym. Bull. 1982, 8, 160-170.

20. Fink, H-P.; Philipp, B.; Paul, D.; Serimaa, R.; Paakkari, T. Polymer 1987, 28, 1265-1270.

21. Krässig, H. A. Polymer Monographs. In Cellulose: Structure, Accessibility and Reactivity; Huglin, M. B., Ed.; Gordon and Breach Science Publishers: Yverdon, Switzerland, 1993; Vol. 11, pp 1-375.

22. Fahmy, Y.; Mobarak, F. Cellul. Chem. Technol. 1971, 6, 61-65.

23. Fengel, D.; Wegener, G. J. Polymer Sci. 1985, 23 (11), 601-602.

24. Hiett, L. A. Tappi J. 1985, 68 (2), 42-48.

25. Ibarra, D.; Köpcke, V.; Ek, M. Holzforschung 2009, 63, 721-730.

26. Iovleva, M. M.; Smirnova, V. N.; Belousova, T. A.; Banduryan, S. I.; Kalashnik, A. T.; Rudinskaya, G. Y. Fibre Chem. 1996, 28 (5), 347-350.

27. Kunze, J.; Fink, H-P. Macromol. Symp. 2005, 223, 175-187.

28. Zhao, H.; Jones, C. L.; Baker, G. A.; Xia, S.; Olubajo, O.; Person, V. N. J. Biotechnol. 2009, 139, 47-54.

29. Ye, D.; Farriol, X. Cellulose 2005, 12, 507-515.

30. Fernandes Diniz, J. M. B.; Gil, M. H.; Castro, J. A. A. M. Wood Sci. Technol. 2004, 37, 489-494.

31. Oksanen, T.; Buchert, J.; Viikari, L. Holzforschung 1997, 51, 355-360.

32. Zhang, Y. H. P.; Lynd, L. R. Biotechnol. Bioeng. 2004, 88 (7), 797-824.

33. Rabinovich, M. L.; Melnick, M. S.; Bolobova, A. V. Appl. Biochem. Microbiol. 2002, 38 (4), 305-321.

34. Engström, A. C.; Ek, M.; Henriksson, G. Biomacromolecules 2006, 7, 2027-2031.

35. Henriksson, G.; Christiernin, M.; Agnemo, R. J. Ind. Microbiol. Biotechnol. 2005, 32 (5), 211-214.

36. Ibarra, D.; Köpcke, V.; Ek, M. Enzyme Microb. Technol. 2010, 47, 355-362.

37. Ibarra, D.; Köpcke, V.; Larsson, P. T.; Jääskeläinen, A-S.; Ek, M. Bioresour. Technol. 2010, 101, 7416-7423. 
38. Köpcke, V.; Ibarra, D.; Ek, M. Nord. Pulp Pap. Res. J. 2008, 23 (4), 363-368.

39. Köpcke, V.; Ibarra, D.; Larsson, P. T.; Ek, M. Nord. Pulp Pap. Res. J. 2010, 25 (1), 191-198.

40. Köpcke, V.; Ibarra, D.; Larsson, P. T.; Ek, M. Polym. Renewable Resour. 2010, 1 (1), 17-34.

41. Li, D. Master Thesis, Royal Institute of Technology, Stockholm, Sweden, 2010.

42. Najar, H. Master Thesis, Royal Institute of Technology, Stockholm, Sweden, 2009.

43. Carrard, G.; Koivula, A.; Söderlund, H.; Béguin, P. Proc. Natl. Acad. Sci. 2000, 97 (19), 10342-10347.

44. Lynd, L. R.; Weimer, P. J.; van Zyl, W. H.; Pretorius, I. S. Microbiol. Mol. Biol. Rev. 2002, 66 (3), 506-577.

45. Rabinovich, M. L.; Melnick, M. S.; Bolobova, A. V. Biokhimiya (Moscow, Russian Federation) 2002, 67 (8), 850-871.

46. Eremeeva, T.; Bikova, T.; Eismonte, M.; Viesturs, U.; Treimanis, A. Cellulose 2001, 8 (1), 69-79.

47. Fock, W. Papier 1959, 13, 92-95.

48. Hopner, T.; Jayme, G.; Urich, J. C. Papier 1955, 9, 476-482.

49. Nelson, M. L.; Rousselle, M. A.; Cangemi, S. J.; Trouard, P. Text. Res. J. 1970, 40 (10), 872-880.

50. Fischer, S.; Schenzel, K.; Fischer, K.; Diepenbrock, W. Macromol. Symp. 2005, 223, 41-56.

51. Filpponen, I.; Argyropoulos, D. S. Ind. Eng. Chem. Res. 2008, 47 (22), 8906-8910.

52. Elg Christoffersson, K.; Sjöström, M.; Edlund, U.; Lindgren, Å.; Dolk, M. Cellulose 2002, 9, 159-170.

53. Sixta, H. Chemical Pulping. In Handbook of Pulp; Wiley-VCH Verlag: Weinheim, Germany, 2006; pp 3-19.

54. Vila, C.; Santos, V.; Parajo, J. C. J. Chem. Technol. Biotechnol. 2004, 79, 1098-1104.

55. Sixta, H.; Harms, H.; Dapia, S.; Parajo, J. C.; Puls, J.; Saake, B.; Fink, H-P.; Röder, T.Cellulose 2004, 11 (1), 73-83.

56. Christov, L. P.; Prior, B. A. Biotechnol. Lett. 1993, 15 (12), 1269-1274.

57. Hillman, D. Paper Asia 2006, 12-18.

58. Drexler, H.; Ulm, K.; Hubmann, M.; Hardt, R.; Göen, T.; Mondorf, W.; Lang, E.; Angerer, J.; Lehnert, G. Int. Arch. Occup. Environ. Health 1995, 67, 243-252.

59. Rosenau, T.; Potthast, A.; Sixta, H.; Kosma, P. Prog. Polym. Sci. 2001, 26 (9), 1763-1837.

60. Hermanutz, F.; Meister, F.; Uerdingen, E. Chem. Fibers Int. 2006, 6, 342-344.

61. Swatloski, R. P.; Rogers, R. D.; Holbrey, J. D. U.S. Patent 6,824,599, 2003.

62. Dadi, A. P.; Varanasi, S.; Schall, C. A. Biotechnol. Bioeng. 2006, 95, 904-910. 
63. Zhu, S.; Wu, Y.; Chen, Q.; Yu, Z.; Wang, C.; Jin, S.; Ding, Y.; Wu, G. Green Chem. 2006, 8, 325-327.

64. Ebner, G.; Schiehser, S.; Potthast, A.; Rosenau, T. Tetrahedron Lett. 2008, 49, 7322-7324.

65. Liu, Z.; Wang, H.; Li, Z.; Lu, X.; Zhang, X.; Zhang, S.; Zhou, K. Mater. Chem. Phys. 2011, 128, 220-227.

66. Janzon, R.; Puls, J.; Saake, B. Holzforschung 2006, 60 (4), 347-354.

67. Janzon, R.; Puls, J.; Bohn, A.; Potthast, A.; Saake, B. Cellulose 2008, 15 (5), 739-750.

68. Puls, J.; Janzon, R.; Saake, B. Lenzinger Ber. 2006, 86, 63-70.

69. Jackson, L. S.; Heitmann, J. A.; Joyce, T. W. Tappi J. 1998, 81 (3), 171-178.

70. Hyatt, J. A.; Fengel, R. W.; Edgar, K. J.; Alvarez-Wright, M. T. U.S. Patent 6,057,438, 2000.

71. Stephens, R. S. Patent WO/1999/016960, 1999.

72. Gübitz, G. M.; Lischnig, T.; Stebbing, D.; Saddler, J. N. Biotechnol. Lett. 1997, 19 (5), 491-495.

73. Oksanen, T.; Pere, J.; Buchert, J.; Viikari, L. Cellulose 1997, 4 (4), 329-339.

74. Salmén, L.; Olsson, A. M. J. Pulp Pap. Sci. 1998, 24, 99-103.

75. Sykes, M.; Klungness, J. H.; Abubakr, S.; Tan, F. Prog. Pap. Recycl. 1996, 39-46.

76. Kvarnlöf, N. Ph.D. Thesis, Karlstad University, Karlstad, Sweden, 2007. 